\title{
HUBUNGAN DUKUNGAN KELUARGA DENGAN TINGKAT KEMANDIRIAN PERSONAL HYGIENE ANAK TUNAGRAHITA DI SLB TUNAS MULYA KELURAHAN SEMEMI KECAMATAN BENOWO
}

\author{
Oktavia Alfita Sari, Wesiana Heris Santy \\ Fakultas Kebidanan dan Keperawatan \\ Universitas Nahdlatul Ulama Surabaya, Jalan Smea 57 Surabaya \\ wesiana@unusa.ac.id
}

\begin{abstract}
: children with mental retardation are remarkable because they have limitations compared to normal children, both in terms of physical, intellectual, social, economic, but still can be trained to be independent. To be able to master the ability of good personal hygiene is needed supports from the Parents. This study aims to determine the relationship of family support with personal hygiene level of independence of children with intellectual challenges in SLB Tunas Mulya Kelurahan Sememi kecamatan Benowo. The research design was qualitative analytic using cross sectional approach. The population were 27 parents with simple random sampling method where it gets 25 parents. Family support dependent variable and the independent variable degree of independence tunagrahita personal hygiene. Collecting data using questionnaires and research analysis using Rank Spearman with the correlation level $\alpha=0.05$. The results of the 25 respondents obtained the majority (52\%) of respondents give good support, nearly half (44\%) of respondents are quite independent, the test results Spearman Rank Correlation P Value $=0,030$ so that $\rho$ $<\alpha$ then $\mathrm{HO}$ is rejected means that there is a relationship between support families with tunagrahita children's personal hygiene level SLB Tunas Mulya Kelurahan Sememi Kecamatan Benowo. The conclusion of this research was good supports make children with mental retardation independent enough, so it is suggested to well support in order to make the children with mental retardation independent.
\end{abstract}

Keywords: family, children, retardation, hygiene

\begin{abstract}
Abstrak: Anak penyandang tunagrahita tergolong anak mempunyai kekurangan atau keterbatasan dibanding anak normal, baik dari segi fisik, intelektual, sosial, ekonomi, namun masih dapat dilatih untuk mandiri. Untuk dapat menguasai kemampuan personal hygiene dengan baik diperlukan dukungan dari orang tua. Tujuan penelitian ini untuk mengetahui hubungan dukungan keluarga dengan tingkat kemandirian personal hygiene anak tunagrahita di SLB Tunas Mulya Kelurahan Sememi kecamatan Benowo Jenis penelitian adalah analitik dengan menggunakan pendekatan cross sectional. Populasi sebesar 27 orangtua dengan teknik pengambilan sampel yang digunakan adalah simple random sampling yang didapatakan sampel sebesar 25 orang tua. Variabel dependen dukungan keluarga dan variabel independen tingkat kemandirian personal hygiene anak tunagrahita. Pengumpulan data menggunakan kuesioner. Analisa penelitian menggunakan Uji Korelasi Rank Spearman dengan tingkat kemaknaannya $\alpha=0,05$. Hasil penelitian dari 25 responden diperoleh sebagian besar (52\%) responden memberikan dukungan baik, hampir setengahnya (44\%) responden cukup mandiri, hasil Uji Korelasi Rank Spearman dengan $P$ Value $=0,030$ sehingga $\rho<\alpha$ maka $\mathrm{H}_{0}$ di tolak berarti ada hubungan antara dukungan keluarga dengan tingkat kemandirian personal hygiene anak tunagrahita SLB Tunas Mulya Keluraha Sememi Kecamatan Benowo. Kesimpulan penelitian adalah dukungan baik masih menjadikan anak tunagrahita cukup mandiri. Sehingga disarankan dukungan sangat baik untuk dapat membuat anak tunagrahita menjadi mandiri.

Kata Kunci: Dukungan keluarga, Tingkat Kemandirian Personal Hygiene, Tunagrahita
\end{abstract}




\section{PENDAHULUAN}

Anak tunagrahita dapat dikatakan mempunyai kekurangan atau keterbatasan dari segi mental intelektualnya (di bawah rata-rata normal) sehingga mengalami kesulitan dalam mengerjakan tugas-tugas akademik, menjalin komunikasi, serta berhubungan sosial (Putranto, 2015). Masih adanya stigma yang buruk dari keluarga dengan menganggap anak tunagrahita tidak bisa mengurus diri sendiri, keluarga berasumsi pekerjaan yang dilakukan anak dalam mengurus diri belum memberikan hasil yang baik dan benar, sehingga keluarga belum optimal dalam memberikan dukungan kepada anak mereka. Depkes RI, 2007 menyatakan anak tunagrahita mengalami kesulitan dalam membina hidup seharihari yang berkaitan dengan mengurus diri, menolong diri, dan merawat diri.

Hasil penelitian yang dilakukan oleh Rahmawati 2011 dari 65 sample didapatkan kemapuan perawatan diri anak rendah dengan hasil 40 responden $(61,6 \%)$, kemudian kemampuan perawatan diri anak tinggi dengan hasil 25 responden $(38,4 \%)$. Hasil tersebut menunjukkan kemampuan perawatan diri anak tunagrahita terkategorikan rendah.

Menurut data Sensus Nasional Biro Pusat Statistik tahun 2007 jumlah penyandang cacat di Indonesia sebesar $0,7 \%$ dari jumlah penduduk sebesar 211.428 .572 atau sebanyak 1.480 .000 jiwa. Dari jumlah tersebut $24,45 \%$ atau 361.860 diantaranya adalah anak-anak usia 0-18 tahun dan 21,42\% atau 317.016 anak, merupakan anak cacat usia sekolah (5-18 tahun). Sekitar 66.610 anak sekolah penyandang cacat $(14,4 \%$ dari seluruh anak penyandang cacat) ini terdaftar di Sekolah Luar Biasa. Ini berarti masih ada 295.250 anak penyandang cacat $(85,6 \%)$ ada di masyarakat dibawah pembinaan dan pengawasan orang tua dan keluarga.

Kemudian diketahui data dari salah satu sekolah di Surabaya tepatnya pada SLB Tunas Mulya pada tahun 2015 terdapat 27 siswa tunagrahita dengan tingkat SD. Setelah dilakukan wawancara dengan 6 wali murid dari anak tunagrahita, 2 orang tua mengatakan anak mereka sudah dapat melakukan personal hygiene secara mandiri tanpa perlu bantuan orang tua seperti melakukan mandi sendiri, menggosok gigi sendiri, sedangkan 4 orang tua dari anak tunagrahita mengatakan bahwa anak mereka masih memerlukan bantuan, seperti mandi apabila di biarkan anak hanya akan bermain air bukan melakukan mandi, memakai sabun hanya sekedar dipakai tidak sampai benar-benar bersih, untuk menggosok gigi terkadang orang tua perlu mengulanginya kembali dikarenakan kurang bersih, dan tidak semua anak dapat memakai baju yangberkancing.

Kemandirian

bukanlah keterampilan yang muncul secara tibatiba tetapi perlu diajarkan dan dilatih pada anak agar tidak menghambat tugastugas perkembangan anak selanjutnya. Menurut Wiyani (2013) Beberapa faktor yang mendukung kemandirian anak adalah faktor internal yaitu fisiologis dan psikologis, faktor eksternal yaitu lingkungan, cinta dan kasih sayang, pola asuh (dukungan keluarga), pengalaman dalam kehidupan. Anak tunagrahita yang tidak mendapatkan intervensi secara terus menerus dari lingkungan berdampak berlambannya anak menjadi mandiri, untuk membuat anak mampu menjadi mandiri maka dibutuhkan adanya dukungan dari orang tua. Dukungan sendiri memiliki empat jenis yaitu: dukungan instrument, dukungan informasional, dukungan penilaian, dukungan emosional (Harnilawati, 2013).

Orang tua dengan anak tunagrahita dalam melatih kemandirian anak, sesekali kita harus membiarkan anak melakukan apa yang mungkin bisa mereka lakukan, jangan terlalu memanjakkan hanya karena mereka mempunyai kecerdasan jauh di bawah 
normal. Berfikirlah bahwa anak mampu melakukan apa yang kiranya mereka akan lakukan, berikan rasa percaya pada anak (Subini, 2012).Berdasarkan dengan uraian diatas maka peneliti tertarik untuk melakukan penelitian mengenai hubungan dukungan keluarga dengan tingkat kemandirian personal hygiene pada tunagrahita di SLB Tunas Mulya kelurahan sememi kecamatan benowo.

\section{METODE}

Metode penelitian yang digunakan adalah analitik dengan pendekatan cross sectional yaitu untuk mengetahui hubungan dukungan keluarga dengan tingkat kemandirian personal hygiene anak tunagrahita.

Penelitian dilakukan di SLB Tunas Mulya Kelurahan Sememi Kecamatan Benowo pada bulan April 2016. Populasi pada penelitian ini yaitu seluruh orangtua yang mempunyai anak tunagrahita tingkat SD di SLB Tunas Mulya. Sampel penelitian ini adalah orangtua dari anak tunagrahita yang bersekolah di SLB Tunas Mulya Kelurahan Sememi Kecamatan Benowo sebanyak 25 responden.

Pengambilan sampel menggunakan teknik simple random sampling, yaitu sampel diambil secara acak, dari 27 populasi akan diambil 25 responden dengan cara di lotre yang dimana nama keluar tidak dijadikan responden. Instrument penelitian ini menggunakan kuisioner dukungan keluarga dan tingkat kemandirian personal hygiene.

\section{HASIL \& PEMBAHASAN \\ Hasil}

Pengumpulan data responden meliputi pekerjaan orang tua, pendidikan terakhir orang tua, dukungan keluarga, tingkat kemandirian personal hygiene.

a. Karakteristik responden berdasarkan pekerjaan orang tua
Tabel 5.1 Distribusi frekuensi responden berdasarkan pekerjaan orang tua di SLB Tunas Mulya Kelurahan Sememi Kecamatan Benowo

\begin{tabular}{|l|l|l|}
\hline Pekerjaan & Frekuensi & Persentase \\
\hline Tidak bekerja & 2 & 8 \\
Bekerja & 23 & 92 \\
\hline Total & 25 & $100(\%)$ \\
\hline
\end{tabular}

Sumber data primer : April 2016

Dari tabel 5.1 dapat diketahui bahwa 25 responden terdapat sebagian besar 23 $(92 \%)$ responden bekerja

b. Karakteristik responden berdasarkan pendidikan terakhir orang tua

Tabel 5.2 Distribusi frekuensi responden berdasarkan pendidikan orang tua di SLB Tunas Mulya Kelurahan Sememi Kecamatan Benowo

\begin{tabular}{|l|l|l|}
\hline Pendidikan & Frekuensi & Presentase \\
\hline SD-SMP & 4 & 16 \\
SMA & 15 & 60 \\
PT & 6 & 24 \\
\hline Total & 25 & 100 \\
\hline
\end{tabular}

Sumber data primer : April 2016

Tabel 5.2 Menunjukkan bahwa sebagian besar $15(60 \%)$ responden responden berpendidikan SMA dan setara.

c. Karakteristik responden berdasarkan dukungan keluarga

Dibawah ini merupakan tabel distribusi responden berdasarkan dukungan keluarga

Tabel 5.5 Distribusi responden berdasarkan dukungan keluarga di SLB Tunas Mulya Kelurahan Sememi Kecamatan Benowo

\begin{tabular}{|l|l|l|}
\hline $\begin{array}{l}\text { Dukungan } \\
\text { Keluarga }\end{array}$ & $\begin{array}{l}\text { Frekuensi } \\
(\mathrm{N})\end{array}$ & $\begin{array}{l}\text { Persentase } \\
(\%)\end{array}$ \\
\hline Kurang & 0 & 0 \\
Cukup & 12 & 48 \\
Baik & 13 & 52 \\
\hline Total & 25 & $100(\%)$ \\
\hline
\end{tabular}

Sumber data primer : April 2016

Dari tabel 5.3 Dapat diketahui bahwa 25 responden, terdapat sebagian besar 13 
(52\%) responden memberikan dukungan keluarga baik.

d. Karakteristik responden berdasarkan tingkat kemandirian personal hygiene Dibawah ini merupakan tabel distribusi responden berdasarkan tingkat kemandirian anak

Tabel 5.4 Distribusi responden berdasarkan tingkat kemandirian anak di SLB Tunas Mulya kelurahan Sememi Kecamatan Benowo

\begin{tabular}{|l|l|l|}
\hline Kemandirian & Frekuensi & Persentase \\
\hline Tidak mandiri & 8 & 32 \\
Cukup mandiri & 11 & 44 \\
Mandiri & 6 & 24 \\
\hline Total & 25 & 100 \\
\hline
\end{tabular}

Sumber data primer : April 2016

Dari tabel 5.4 Dapat diketahui bahwa 25 responden, terdapat hampir setengahnya $11(44 \%)$ responden cukup mandiri.

\section{e. Tabulasi silang}

Tabel 5.5 Tabulasi silang hubungan dukungan keluarga dengan tingkat kemandirian personal hygiene anak tunagrahita di SLB Tunas Mulya Kelurahan Sememi Kecamatan Benowo

\begin{tabular}{|c|c|c|c|c|}
\hline \multirow{2}{*}{$\begin{array}{l}\text { Dukungan } \\
\text { Keluarga }\end{array}$} & \multicolumn{3}{|c|}{ Kemandirian } & \multirow[t]{2}{*}{ Total } \\
\hline & $\begin{array}{c}\text { Tidak } \\
\text { mandiri }\end{array}$ & $\begin{array}{l}\text { Cukup } \\
\text { mandiri }\end{array}$ & Mandiri & \\
\hline Kurang & 0 & 0 & 0 & 0 \\
\hline Cukup & $\begin{array}{c}6 \\
(50 \%)\end{array}$ & $\begin{array}{c}5 \\
(41,7 \%)\end{array}$ & $\begin{array}{c}1 \\
(8,3 \%)\end{array}$ & $\begin{array}{c}12 \\
(100 \\
\%)\end{array}$ \\
\hline Baik & $\begin{array}{c}2 \\
(15,4 \%)\end{array}$ & $\begin{array}{c}6 \\
(46,2 \%)\end{array}$ & $\begin{array}{c}5 \\
(38,5 \%)\end{array}$ & $\begin{array}{c}13 \\
(100 \\
\%)\end{array}$ \\
\hline Total & $\begin{array}{c}8 \\
(32 \%)\end{array}$ & $\begin{array}{c}11 \\
(44 \%)\end{array}$ & $\begin{array}{c}6 \\
(24 \%)\end{array}$ & $\begin{array}{c}25 \\
(100 \\
\%)\end{array}$ \\
\hline
\end{tabular}

Sumber data primer : April 2016

Berdasarkan tabel 5.5 Menunjukkan bahwa dari 25 responden, terdapat 13 $(100 \%)$ keluarga dengan dukungan keluarga baik $6(46,2 \%)$ anak cukup mandiri, dari 12 (100\%) keluarga dengan dukungan keluarga cukup $6(50 \%)$ anak tidak mandiri.

\section{PEMBAHASAN}

a. Dukungan Keluarga

Dukungan keluarga dalam personal hygiene anak merupakan bagian yang penting karena keluarga adalah pihak yang selalu berada dekat dengan anak. Dukungan keluarga mengenai personal hygiene yang baik tentunya dapat meningkatkan status kesehatan anak melalui praktik personal hygiene.

Berdasarkan hasil penelitian di SLB Tunas Mulya Kelurahan Sememi Kecamatan Benowo Surabaya dari 25 responden sebagian besar $13 \quad(52 \%)$ responden memberikan dukungan keluarga baik, sedangkan sebanyak 12 (48\%) responden memberikan dukungan keluarga cukup. Untuk dukungan keluarga yang paling banyak diberikan orangtua adalah dukungan instrument, dengan total nilai 260. Hal ini peneliti berasumsi bahwa keluarga telah menyediakan apa yang dibutuhkan anak tunagrahita sehingga hal tersebut berpengaruh positif terhadap perkembangan terutama kemampuan anak dalam personal hygiene. Menurut Smet (1994) dalam buku Harnilawati (2013), dukungan instrument bertujuan untuk mempermudah seseorang dalam melakukan aktivitasnya berkaitan dengan persoalan-persoalan yang dihadapinya, atau menolong secara langsung kesulitan yang dihadapi, misalnya menyediakan peralatan lengkap dan memadai bagi keluarga.

Sedangkan jenis dukungan keluarga yang paling sedikit diberikan orang tua kepada anak adalah dukungan penilaian dengan total nilai 221. Hal ini dapat disimpulkan bahwa keluarga belum maksimal dalam memberi kepercayaan dan menerima a 74 tunagrahita untuk melakukan personal hygiene sendiri. Kepercayaan yang diberikan orang tua kepada anak dapat menumbuhkan rasa percaya diri pada anak, dan memberikan apresiasi apabila anak dapat melakukan tindakan personal hygiene secara baik juga dapat membuat 
anak menjadi lebih bersemangat, serta merasa lebih termotivasi. Menurut Smet (1994) dalam buku Harnilawati (2013),

Dukungan penilaian yaitu bentuk penghargaan diberikan seseorang kepada pihak lain berdasarkan kondisi sebenarnya. Sebagai pemberi bimbingan dan umpan balik atas pencapaian yang dilakukan seseorang dengan cara memberikan support, pengakuan, penghargaan, dan perhatian sehingga dapat menimbulkan kepercayaan diri pada individu. Penilaian dapat berupa positif dan negatif yang mana pengaruhnya sangat berarti bagi seseorang, berkaitan dengan dukungan keluarga maka penilaian sangat membantu adalah penilaian positif.

Banyak faktor yang mempengaruhi dukungan keluarga, faktor yang mempengaruhi dukungan keluarga menurut Purnawan (2006), yaitu internal dan eksternal.Faktor internal meliputi tahap perkembangan, pendidikan dan tingkat pengetahuan, faktor emosi, spiritual, dan faktor eksternal adalah praktik dukungan di keluarga, sosial ekonomi, latar belakang budaya.Karakteristik responden orang tua berdasarkan pendidikan terbanyak adalah SMA 15 (60\%), tingkat pendidikan perguruan tinggi 6 (24\%), sedangkan tingkat pendidikan yang terendah adalah SMP 4 (16\%). Hal ini menunjukkan bahwa tingkat pendidikan orang tua anak tunagrahita sudah baik dikarenakanpendidikan orang tua juga mempengaruhi dalam dukungan diberikan dalam hal tingkat kemandirian anak melakukan personal hygiene. Karena dengan pendidikan tersebut, orang tua mampu dan lebih mudah mendapatkan dan menerima informasi dari luar seperti lingkungan sekitar atau pihak sekolah tempat anak mendapatkan ilmu terutama mengenai cara menjaga kesehatan (personal hygiene), membimbing anak dengan baik.
Hal ini sejalan dengan pendapatnya Apriyanto (2012), semakin baik tingkat pengetahuan keluaraga maka semakin baik dampaknya bagi perkembangan anak dan semakin rendah tingkat pengetahuan keluarga semakin buruk dampaknya bagi anak, sehingga tingkat pendidikan yang rendah berdampak pada kurangnya pengetahuan keluarga tentang kebutuhan-kebutuhan tunagrahita dan cara mendidik tunagrahita sehingga rasa kasih sayang dan perhatian keluarga terhadap anak juga berkurang. Dikarenakan semakin tinggi tingkat pendidikan seseorang, maka akan semakin mudah menerima informasi, sehingga makin banyak pula pengetahuan yang dimiliki, dan pendidikan yang kurang akan menghambat perkembangan sikap seseorang terhadap nilai-nilai yang baru diperkenalkan.

Faktor selanjutnya yang mempengaruhi dukungan keluarga yaitu faktor sosial ekonomi, dari hasil penelitian telah didapatkan 23 (92\%) responden bekerja yang dimana orang tua dapat dikatakan telah sibuk dengan aktivitas pekerjaannya akan tetapi dengan hasil dukungan baik, membuktikan mereka masih dapat meluangkan waktu untuk mendidik, membimbing, mengasuh anak, mencari tahu akan kondisi anak. Hal ini sesuai dengan teori purnawan (2006) yang menjelaskan semakin tinggi tingkat ekonomi seseorang biasanya akan cepat tanggap terhadap kondisi anak dan segera mencari informasi dan pertolongan ketika anak merasa ada gangguan pada dirinya.

b. Tingkat Kemandirian Personal Hygiene Anak Tunagrahita

Berdasarkan hasil penelitian di SLB Tunas Mulya Kelurahan Sememi Kecamatan Benowo Surabaya didapatkan dari 25 responden hampir setengahnya 11 (44\%) dalam kategori cukup mandiri, dengan hasil jawaban kuesioner terbanyak adalah sering dan kadangkadang sehingga hal ini dikatakan belum 
semua anak tunagrahita dapat melakukan personal hygiene secara mandiri. Untuk hasil sering terbanyak pada item pertanyaan anak mencuci tangan dengan sabun tanpa bantuan, anak mampu memakai-melepas baju dan celana/rok secara mandiri, kemudian hasil terbanyak kadang-kadang saat anak mencuci rambut tanpa bantuan, anak membilas rambutnya dengan bersih saat keramas, anak memasang kancing/resleting sendiri, anak memotong kuku dengan sedikit bantuan

Penelitian ini sesuai dengan penelitian yang dilakukan oleh Puspasari (2012) dengan mendapatkan hasil yang sama pada tingkat kemandirian anak tunagrahita didapatkan hasilcukup mandiri.Untuk dapat melakukan personal hygiene bagi anak tunagrahita maka diperlukan latihan secara terus menerus berbeda dengan anak normal yang diajarkan beberapa kali sudah dapat mengerti dan hafal apa yang diajarkan. Sesuai yang diungkapkan Semiun (2006), menyatakan bahwa anak tunagrahita dengan kemampuan intelektual rendah perlu diajarkan secara terus-menerus dan konsisten agar dapat melakukan keterampilan-keterampilan hidup sederhana seperti perawatan diri dan kegiatan rumah tangga.

Sedangkan menurut pendapat Mohammad, A (2008) yang mengemukakan kemandirian merupakan kemampuan mengurus diri atau memelihara diri sendiri.Meski untuk anak tunagrahita dalam kemandirian mengurus diri masih memerlukan bantuan yang cukup dari orang tua.Kemandirian merupakan salah satu kebutuhan hidup manusia yang sangat penting, begitu pula bagi anak-anak berkebutuhan khusus tidak terkecuali bagi anak-anak tunagrahita. Anak tunagrahita bukan berarti tidak akan mengalami perkembangan kemampuan serta keterampilannya, dengan mendapat pendidikan, bimbingan, pengarahan serta latihan yang insentif, diyakini akan dapat meningkatkan kemampuan serta keterampilan.

Selain itu tingkat kemandirian anak juga ditunjang oleh adanya sarana yang memadai di sekolah dan dirumah, dari pihak SLB Tunas Mulya Kelurahan Sememi Kecamatan Benowo memberikan pembelajaran setiap satu minggu sekali dengan kompetensi bina diri yang akan membantu anak dan mengetahui kemampuan anak yang meliputi merawat diri, mengurus diri, dan menolong diri. Dengan sudah ditunjangnya sarana dan prasarana yang memadai tetap tidak membuat anak tunagrahita untuk mandiri, hal ini tergantung pada anak didik yang bersangkutan dalam menerima stimulus yang didapatkan dari orang tua selama di rumah maupun pembelajaran dari sekolah, dan jangka waktu pembelajaran yang diperoleh.

Menurut Wiyani (2013) yaitu kemandirian anak dipengaruhi oleh beberapa faktor, salah satunya faktor lingkungan. Lingkungan sangat berpengaruh bagi proses pembentukan kemandirian anak. Jika lingkungan sekitar baik menjadikan cepat tercapainya kemandirian anak, pemberian stimulus yang terarah dan teratur di lingkungan keluarga, anak akan lebih cepat mandiri dibanding dengan anak yang kurang mendapatkan stimulus.

c. Hubungan dukungan keluarga dengan tingkat kemandirian personal hygiene anak tunagrahita

Hasil uji Rank Spearman dengan tingkat signifikan yang di analisa menggunakan SPSS for windows. Apabila p sebesar 0,030 sehingga $\mathrm{p}<\alpha$, maka Ho di tolak yang berarti ada hubungan antara dukungan keluarga dengan tingkat kemandirian personal hygiene anak tunagrahita SLB Tunas Mulya Kelurahan Sememi Kecamatan Benowo. Dengan hasil tabulasi silang, dukungan keluarga baik 13 (100\%) menunjukkan tingkat kemandirian anak tunagrahita $6(46,2 \%)$ 
cukup mandiri, dukungan keluarga cukup baik $12(100 \%)$ menunjukkan tingkat kemandirian anak tunagrahita $6(50 \%)$ tidak mandiri. Dari penjelasan di atas bahwa diperlukan dukungan sangat baik untuk dapat meningkatkan kemandirian personal hygiene anak tunagrahita, dikarenakan keluarga merupakan lingkungan yang sangat dekat dengan anak dibanding masyarakat sekitar.Seperti kebiasaan dimana orang tua dalam mempraktikan personal hygiene dihadapan anak dapat mempengaruhi bagaimana anak mendapatkan informasi tentang personal hygiene.Keluarga sebagai tatanan pertama yang mempunyai peran tidak sedikit dalam mengajarkan kebiasaankebiasaan mengenai personal hygiene untuk menumbuhkan kemandirian dalam diri anak.Hal ini sesuai dengan diungkapkan Riza (2012) yang mengatakan dukungan keluarga dapat mempengaruhi kehidupan dan kesehatan anak. Hal ini dapat terlihat bila dukungan keluarga sangat baik maka pertumbuhan dan perkembangan anak relatif stabil, tetapi bila dukungan pada anak kurang baik maka anak akan mengalami hambatan pada dirinya.

Penelitian ini mendapatkan hasil yang sama dengan penelitian dilakukan Arfandi (2013), untuk dukungan sosial keluarga dan kemampuan perawatan diri anak retardasi mental, sehingga ada hubungan yang signifikan antara dukungan sosial keluarga dengan kemampuan perawatan diri pada anak retardasi mental.

Memperoleh kemandirian yang utuh dapat dibentuk dalam karakteristik kepribadian anak. Dengan memberikan kesempatan dan tanggung jawab anak akan mempunyai konsep diri, penghargaan terhadap diri sendiri, dan kemampuan mengatur diri sendiri. Dari pembentukan perilaku ini yang diikuti dengan pembiasaan dan dukungan dari orang terdekat akan menjadikan anak mandiri. Jadi walaupun belum dapat membuat anak tunagrahita mandiri, dukungan keluarga dalam tingkat kemandirian anak tunagrahita tetap dibutuhkan agar dapat meminimalkan ketergantungan anak tunagrahita.Sesuai dengan pendapat Yamin (2010), bahwa perkembangan anak tidak lepas dari pengawasan dan arahan dari orang tua disekitar mereka. Kemandirian menjadi salah satu hal yang sangat penting bagi anak karena ini akan menjadi dasar bagi mereka untuk bertahan hidup sampai dewasa. Dimana saat anak tumbuh maka sedikit demi sedikit anak akan melepas diri dari orang tua dan belajar untuk menghadapi pengalaman yang baru.

\section{SIMPULAN}

1. Dukungan keluarga anak tunagrahita SLB Tunas Mulya Kelurahan Sememi Kecamatan Benowo sebagian besar memberikan dukungan baik.

2. Tingkat kemandirian personal hygiene anak Tunagrahita hampir setengahnya adalah cukup mandiri

3. Ada hubungan dukungan keluarga dengan tingkat kemandirian personal hygiene anak tuangrahita SLB Tunas Mulya Kelurahan Sememi Kecamatan Benowo

\section{Saran}

1. Bagi Peneliti

Diharapkan hasil penelitian ini dapat digunakan sebagai acuan apabila mengadakan penelitian selanjutnya dan untuk menambah wawasan pengetahuan tentang pembuatan skripsi yang lebih baik.

2. Bagi Institusi Pendidikan / SLB (Sekolah Luar Biasa)

Bagi institusi pendidikan khususnya SLB diharapkan dapat terus mengembangkan program pengajaran di sekolah mengenai personal hygiene dengan menambah jam pembelajaran, teori dan praktik seimbang, dan menjalin kerjasama dengan orang tua siswa 
tunagrahita sehingga siswa tunagrahita mendapat bimbingan dan dukungan dibutuhkan pada saat di rumah.

3. Bagi Keluarga

Diharapkan

keluarga meningkatkan dukungan yang diberikan kepada anak, dan dukungan yang belum maksimal dapat dimaksimalkan agar anak menjadi mandiri dalam melakukan tindakan personal hygiene.

\section{DAFTAR PUSTAKA}

Apriyanto, Nunung. (2012). Seluk-Beluk Tunagrahita \& Strategi Pembelajaran.Jogjakarta: Javalitera Arikunto, Suharsimi. (2010). Manajemen Penelitian. Jakarta: Rineka Cipta

Dharma, Kusuma kelana. (2011). Metodologi Penelitian Keperawatan (Pedoman Melaksanakan dan Menerapkan Hasil Penelitian). Jakarta: Trans Info Media

Desmita.(2009).

Psikologi Perkembangan Peserta Didik. Bandung: Remaja Rosdakarya

Dewi, Sofia Rhosma. (2014). Buku Ajar Keperawatan Gerontik. Yogyakarta : Deepublish

Friedman. (2010). Keperawatan Keluarga: Riset, Teori dan Praktik. Jakarta: EGC

Harnilawati. (2013). Konsep dan Proses Keperawatan Keluarga. Sulawesi Selatan: Pusaka As Salam

Hidayat, Aziz Alimun. (2012). Metode Penelitian Keperawatan dan Teknik
Analisis Data. Jakarta: Salemba Medika

Isro'in, Laily; Andarmoyo, Sulistyo. (2012). Personal Hygiene: Konsep, Proses, dan Aplikasi dalam Praktik Keperawatan. Yogyakarta: GrahaIlmu

Kumalasari.(2011). Hubungan Antara Peran Ibu dalam Memenuhi Kebutuhan Dasar (Asah) dengan Kemandirian anak di TK A Dharma Wanita Pesantren Desa Sidoarjo Kecamatan Krian Kabupaten Sidoarjo skripsi. diakses 02 Februari 2016

Lestari, Sri. (2012). Psikologi Keluarga: Penanaman Nilai dan Penanganan Konflik dalam Keluarga. Jakarta: Kencana

Mubarak, Wahit. (2015). Buku Ajar Ilmu Keperawatan Dasar. Jakarta: Salemba Medika

Murtie, Afin. (2014). Ensiklopedi Anak Berkebutuhan Khusus. Jogjakarta: Redaksi Maxima

Notoatmodjo, Soekidjo. (2010). Metodologi Penelitian Kesehatan. Jakarta: Rineka Cipta

Sandra, M. (2010). Anak Cacat Bukan Kiamat: Metode Pembelajaran dan Terapi untuk Anak Berkebutuhan. Yogyakarta: Katahat 